\title{
ECG, LVH and T1 changes in Fabry disease - implications for screening and understanding of the disease model
}

\author{
Rebecca Kozor, Sabrina Nordin*, Amna Abdel-Gadir, Heerajnarain Bulluck, Thomas A Treibel, Charlotte Manisty, \\ James C Moon
}

From 19th Annual SCMR Scientific Sessions

Los Angeles, CA, USA. 27-30 January 2016

\section{Background}

Fabry disease is a rare $\mathrm{X}$-linked condition that results in storage of sphingolipids in multiple organs including the heart. The cardiac phenotype consists mainly of conduction abnormalities, left ventricular hypertrophy (LVH) and disease progression (fibrosis, arrhythmias and heart failure).

CMR LGE classically shows basal inferolateral LGE. Native T1 mapping has recently shown a low T1 likely to represent myocycte storage of fat, even when no $\mathrm{LVH}$ is present. We sought to understand the relationship of storage to LVH and ECG abnormalities.

\section{Methods}

67 genetically confirmed Fabry disease patients underwent CMR (function, T1 mapping, LGE) on a $1.5 \mathrm{~T}$ Siemens Avanto with a concurrent 12 lead ECG. LVH was defined by mass index $\left(\mathrm{LVM}_{\mathrm{i}}\right)$ and a wall thickness $\geq 12 \mathrm{~mm}$. Native T1 mapping used ShMOLLI with a region of interest drawn in the septum in a basal short axis view, and $900 \mathrm{~ms}$ considered the lower limit of normal. An abnormal ECG was defined by a prolonged PR interval (>200 ms), prolonged QRS duration (>120 ms), the presence of T-wave inversions, and/or LVH by Sokolow criteria.

\section{Results}

The 67 Fabry patients had a mean age of $46 \pm 14$ years, females $70 \%$ (47/67), and good LV function (LVEF $76 \pm$ $7 \%)$. LVH was present in $43 \%(29 / 67)$ by wall thickness and $48 \%(32 / 67)$ by mass index.
T1 with LVH: 69\% (46/67) had low native T1 values. Low T1 was more common in $\mathrm{LVH}$ positive than $\mathrm{LVH}$ negative subjects $(86 \%$ vs $55 \%$, mean $854 \pm 53$ vs $897 \pm$ $46 \mathrm{~ms}, \mathrm{p}=0.001)$. However, $55 \%(21 / 38)$ of the LVHnegative subjects had low T1 values, and 14\% (4/29) of LVH-positive subjects had a normal T1.

T1 with ECG: 64\% (43/67) had abnormal ECGs, (Table 1 ; results stratified by $\mathrm{T} 1$ and $\mathrm{LVH}$ ). ECG abnormalities were highly correlated to LVH by wall thickness $(13 \pm 9$ vs $9 \pm 2 \mathrm{~mm}, \mathrm{p}<0.001)$ and $\mathrm{LVM}_{\mathrm{i}}$ $(98 \pm 36$ vs $67 \pm 22 \mathrm{~g} / \mathrm{m} 2, \mathrm{p}=0.001)$ with lower $\mathrm{T} 1$ values in those with ECG abnormalities (863 \pm 52 vs $906 \pm 44 \mathrm{~ms}, \mathrm{p}=0.001)$.

In subjects without $\mathrm{LVH}$, when the T1 was low, 12/21 (58\%) had an abnormal ECG, and 6/17 (33\%) when the T1 was normal.

\section{Conclusions}

In gene positive Fabry disease subjects, LVH has a low T1 $85 \%$ of the time, but half of all LVH-negative patients have a low T1. When there is no LVH, ECG abnormalities are slightly more common in those with a low T1 but up to 1 in 3 have ECG abnormalities before apparent storage. The most plausible explanations for this are either that T1 can miss some storage, or that there may be other Fabry effects other than storage - (toxic metabolites are proposed).

Published: 27 January 2016

Cardiology, Barts Heart Centre, London, United Kingdom 
Table 1 Differences in ECG changes between Fabry patients with and without low T1 values

\begin{tabular}{ccccccc}
\hline & Low T1 & Normal T1 & p-wave & LVH-positive & LVH-negative & p-wave \\
\hline P-wave duration (ms) & $98 \pm 20$ & $85 \pm 24$ & 0.02 & $101 \pm 22$ & $89 \pm 21$ & 0.03 \\
PR interval (ms) & $152 \pm 31$ & $158 \pm 37$ & NS & $156 \pm 29$ & $153 \pm 36$ & NS \\
P-wave to PR interval ratio (\%) & $67 \pm 17$ & $55 \pm 12$ & 0.004 & $67 \pm 20$ & $59 \pm 13$ & 0.05 \\
QRS duration (ms) & $98 \pm 24$ & $86 \pm 11$ & 0.03 & $109 \pm 24$ & $83 \pm 9$ & $<0.001$ \\
T-wave inversions (n) & 25 & 7 & NS & 22 & $33 \pm 14$ & $31 \pm 14$ \\
Sokolow (mm) & $33 \pm 16$ & $29 \pm 10$ & NS & & & NS \\
\hline
\end{tabular}

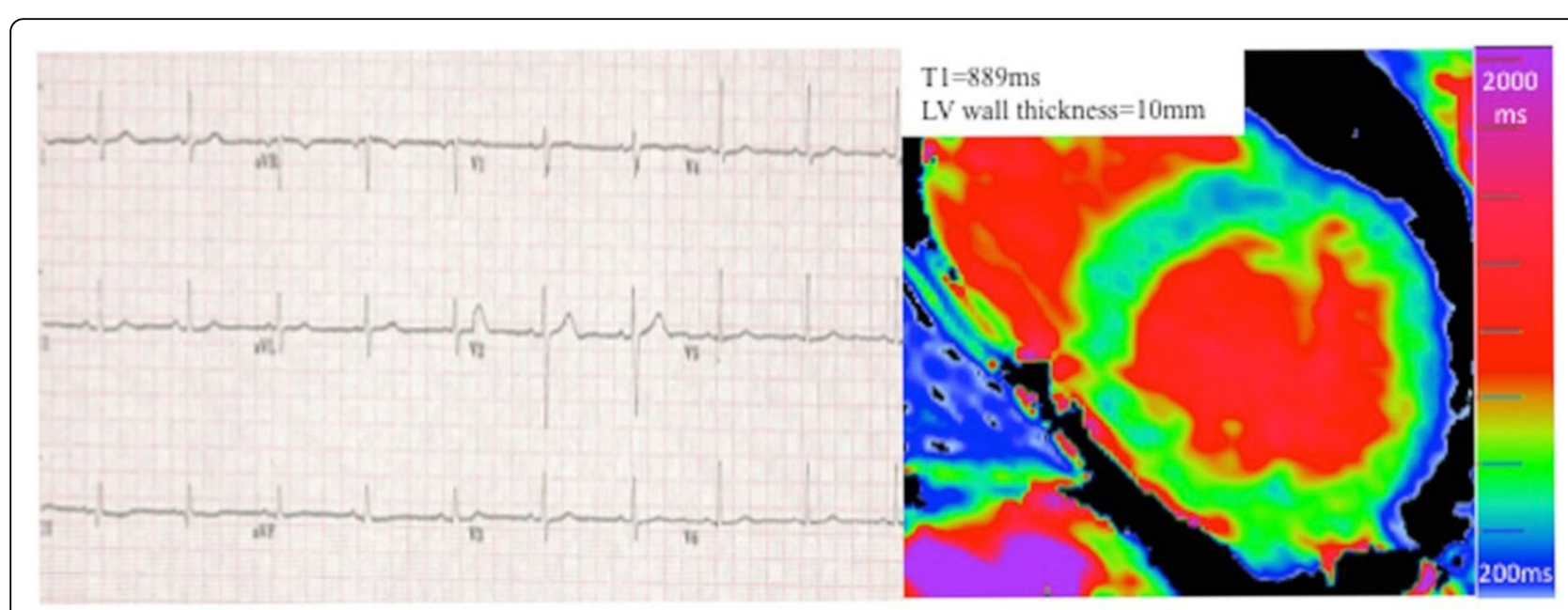

Figure 1 Normal ECG in Fabry disease patient without left ventricular hypertrophy (wall thickness of $10 \mathrm{~mm}$ ) but low T1 of $889 \mathrm{~ms}$

doi:10.1186/1532-429X-18-S1-Q48

Cite this article as: Kozor et al.: ECG, LVH and T1 changes in Fabry

disease - implications for screening and understanding of the disease

model. Journal of Cardiovascular Magnetic Resonance 2016 18(Suppl 1):Q48.

Submit your next manuscript to BioMed Central and take full advantage of:

- Convenient online submission

- Thorough peer review

- No space constraints or color figure charges

- Immediate publication on acceptance

- Inclusion in PubMed, CAS, Scopus and Google Scholar

- Research which is freely available for redistribution 